\title{
EFEKTIVITAS LAYANAN INFORMASI MENGGUNAKAN PENDEKATAN CONTEXTUAL TEACHING AND LEARNING (CTL) DENGAN PRINSIP KONSTRUKTIVISME UNTUK MENGURANGI PROKRASTINASI AKADEMIK SISWA
}

\author{
Nadya Kencana Pramudiastuti ${ }^{1)}$ dan Firman Firman ${ }^{2)}$
}

Abstract: Dewasa ini banyak ditemukan siswa melakukan prokrastinasi akademik seperti melakukan penundaan dalam mengerjakan tugas-tugas akademik, penundaan dalam menghadiri kegiatan belajar di kelas dan mendahulukan aktifitas yang lebih menarik di luar kegiatan akademik. Penelitian ini bertujuan untuk mengungkapkan: (1) prokrastinasi akademik siswa kelompok eksperimen sebelum dan setelah diberi perlakuan layanan informasi menggunakan pendekatan Contextual Teaching and Learning (CTL) dengan prinsip konstruktivisme, (2) prokrastinasi akademik siswa kelompok kontrol tanpa diberi perlakuan layanan informasi menggunakan pendekatan Contextual Teaching and Learning (CTL) dengan prinsip konstruktivisme, (3) perbedaan prokrastinasi akademik siswa kelompok eksperimen yang diberikan layanan informasi menggunakan pendekatan Contextual Teaching and Learning (CTL) dengan prinsip konstruktivisme, dan siswa kelompok kontrol yang tidak diberi perlakuan layanan informasi dengan pendekatan Contextual Teaching and Learning (CTL) dengan prinsip konstruktivisme. Jenis penelitian ini adalah Quasy-Experiment dengan rancangan The Non Equivalent Control Group. Subjek penelitiannya siswa SMA Adabiah 2 Padang kelas X.3 sebagai kelompok eksperimen dan kelas X.4 sebagai kelompok kontrol. Instrumen yang digunakan adalah skala prokrastinasi. Data yang telah dikumpulkan, kemudian dianalisis dengan menggunakan rumus Wilcoxon Signed Ranks test dan Kolmogorov-Smirnov Two Independet Sampel dengan bantuan program Statistical Product and Service Solution (SPSS) versi 20. Temuan dari penelitian ini yaitu: (1) prokrastinasi akademik siswa kelompok eksperimen setelah diberikan layanan informasi menggunakan pendekatan Contextual Teaching and Learning (CTL) dengan prinsip konstruktivisme berada pada kategori rendah dengan skor rata-rata 60,69; (2)prokrastinasi akademik siswa kelompok kontrol yang tidak diberikan layanan informasi menggunakan pendekatan Contextual Teaching and Learning (CTL) dengan prinsip konstruktivisme berada pada kategori sedang dengan skor rata-rata 88,82; (3) terdapat perbedaan yang signifikan pengurangan prokrastinasi akademik siswa pada kelompok eksperimen dengan kelompok kontrol.

\section{Keywords: Layanan informasi, contextual teaching and learning, prinsip konstruktivisme,} prokrastinasi akademik

\section{PENDAHULUAN}

Sekolah sebagai salah satu lembaga pendidikan memiliki tanggung jawab yang besar dalam proses pencapaian tujuan pendidikan dengan menyelenggarakan pendidikan formal dan beberapa program untuk memberikan pembelajaran yang berkualitas bagi peserta didik. Untuk mewujudkan hal itu diperlukan tenaga pendidik yang profesional di bidang keilmuannya masing-masing, termasuk salah satunya guru bimbingan dan konseling/konselor. Sebagaimana telah dikemukakan dalam Undang-Undang No 20 Tahun 2003 Pasal 1 ayat 6 , bahwa konselor adalah pendidik. Dengan demikian pelayanan konseling adalah pelayanan pendidikan yang dapat diberikan melalui sepuluh jenis layanan bimbingan dan konseling dalam rangka meningkatkan mutu pendidikan nasional.

\footnotetext{
${ }^{1}$ Nadya Kencana Pramudiastuti, Jurusan Bimbingan dan Konseling, Fakultas Ilmu Pendidikan Universitas Negeri Padang.

${ }^{2}$ Firman(2), Jurusan Bimbingan dan Konseling, Fakultas Ilmu Pendidikan Universitas Negeri Padang
} 
Tugas guru bimbingan dan konseling/konselor sesuai dengan Peraturan Menteri Pendidikan Nasional Nomor 27 tahun 2008 tentang Standar Kualifikasi Akademik dan Kompetensi Konselor adalah untuk mendukung perkembangan pribadi para pelajar sesuai dengan kebutuhan, bakat, minat dan kepribadian mereka. Pelayanan yang diberikan oleh guru bimbingan dan konseling/konselor kepada siswa asuh, baik secara perorangan, kelompok maupun klasikal, agar siswa mampu mandiri dan berkembang secara optimal sesuai dengan tujuan yang ingin dicapai melalui pelayanan bimbingan dan konseling.

Salah satu layanan bimbingan dan konseling yang harus diselenggarakan di sekolah adalah layanan informasi. Layanan informasi merupakan layanan bimbingan dan konseling yang membantu siswa menerima dan memahami berbagai informasi diri, sosial, karir/jabatan dan pendidikan lanjutan. Prayitno (2012:49) menjelaskan bahwa informasi sangat diperlukan oleh individu sebagai acuan untuk bersikap dan bertingkah laku sehari-hari, sebagai pertimbangan bagi arah pengembangan diri, dan sebagai dasar pengambilan keputusan. Maka dari itu, layanan informasi bertujuan agar informasi yang disampaikan dapat dikuasai oleh siswa dan dijadikan sebagai acuan dalam bertingkah laku sehari-hari, sebagai arah pertimbangan diri dan sebagai dasar pengambilan keputusan.

Layanan informasi yang diberikan secara klasikal di kelas tentunya harus dikemas semenarik mungkin agar siswa lebih bersemangat dalam mengikuti prosesnya dan dapat menguasai informasi yang disampaikan serta mengaplikasikan pengetahuan yang diperoleh ke dalam kehidupan sehari-hari. Maka dari itu dalam pemberian layanan informasi perlu diterapkan pendekatan pembelajaran yang bervariasi serta pemanfaatan media yang beragam. Salah satu pendekatan yang dapat diterapkan dalam pemberian layanan informasi adalah Contextual Teaching and Learning (CTL).

Wina (2006:53) menyatakan Contextual Teaching and Learning adalah suatu strategi pembelajaran yang menekankan pada proses keterlibatan siswa secara penuh untuk dapat menemukan materi yang dipelajari dan menghubungkannya dengan situasi kehidupan nyata sehingga mendorong siswa untuk dapat menemukan materi yang dipelajari dan menghubungkannya dengan situasi kehidupan nyata dan sehingga mendorong siswa untuk dapat menerapkannya dalam kehidupan mereka. CTL akan menjadikan pembelajaran menjadi lebih bermakna karena siswa lebih aktif dan pengetahuan yang dibahas disesuaikan dengan kehidupan nyata siswa.
Penelitian Innayatun Naim (2012) yang dilaksanakan pada siswa kelas VIII SMP Ali Ma'sum Krapyak Yogyakarta menunjukkan bahwa pembelajaran matematika menggunakan pendekatan kontekstual melalui metode Teams Games Tournament (TGT) efektif terhadap pemahaman konsep dan peningkatan motivasi belajar siswa.

Berdasarkan temuan penelitian tersebut, dapat dipahami bahwa pendekatan kontekstual dapat menjadi pilihan dalam menyelenggarakan pembelajaran klasikal yang bermakna dan menyenangkan bagi siswa karena selain dapat meningkatkan hasil belajar siswa, pendekatan kontekstual ternyata juga dapat meningkatkan motivasi belajar siswa. Kemudian pendekatan kontekstual juga memiliki keunggulan lain seperti memberikan siswa kesempatan untuk lebih aktif terlibat secara penuh dalam proses pembelajaran, mendorong siswa untuk menghubungkan pengetahuan yang dimilikinya dengan kondisi nyata yang dialaminya dalam kehidupan sehari-hari. Hal ini berarti bahwa pendekatan Contextual Teaching and Learning (CTL) dapat diaplikasikan dalam layanan klasikal seperti layanan informasi agar informasi yang disampaikan dapat dikuasai oleh siswa kemudian dijadikan sebagai acuan dalam bertingkah laku di kehidupan sehari-hari, sesuai dengan tujuan yang ingin dicapai melalui pemberian layanan informasi.

Pendekatan Contextual Teaching and Learning (CTL) memiliki tujuh prinsip yang dapat diaplikasikan dalam pembelajaran klasikal sesuai dengan yang dijelaskan oleh Rusman (2012) yaitu konstruktivisme, menemukan (inquiry), bertanya (questioning), masyarakat belajar (learning community), pemodelan (modeling), refleksi (reflection), Penilaian Sebenarnya (Authentic Assessment). Namun dalam penelitian ini penulis hanya akan memfokuskan pada prinsip konstruktivisme dangan pertimbangan bahwa konsep konstruktivisme merupakan dasar pemikiran dari pendekatan Contextual Teaching and Learning (CTL). Pada dasarnya dalam prinsip konstruktivisme juga tercakup prinsip inquiry, questioning, dan refleksi yang dapat diaplikasikan dalam pemberian layanan informasi di kelas.

Salah satu layanan bimbingan dan konseling yang telah terlaksana di SMA Adabiah 2 Padang adalah layanan informasi yang diberikan secara klasikal selama 1 jam pelajaran tatap muka di kelas. Namun, layanan informasi yang diberikan oleh guru bimbingan dan konseling dirasa belum maksimal kualitas pelaksanaannya dan belum memberikan pengaruh yang begitu besar bagi kehidupan pribadi siswa. Hal ini disebabkan oleh fasilitas pembelajaran yang belum merata untuk setiap 
kelas. Sehingga guru bimbingan konseling pun kesulitan dalam menerapkan metode yang bervariasi serta menggunakan media yang dapat menunjang kegiatan pembelajaran klasikal melalui layanan informasi. Pada akhirnya pemberian layanan informasi hanya dilakukan dengan metode ceramah dan hal ini membuat siswa tidak bersemangat dan tidak betah berada di dalam kelas selama pelaksanaan layanan informasi.

Prayitno (2002:1) menjelaskan bahwa salah satu faktor penentu kesuksesan peserta didik adalah sejauh mana peserta didik mampu menyelesaikan dengan baik tugas-tugas yang dituntut oleh pendidik. Baik tidaknya penyelesaian tugas oleh siswa dapat dilihat dari ketepatan waktu dalam pengumpulan tugas dan mutu/kualitas tugas yang telah diselesaikan.

Kondisi baik yang berkembang di kalangan siswa saat ini masih ada siswa yang memiliki kebiasaan belajar yang baik yaitu menyelesaikan tugas tepat pada waktunya meskipun banyak tugas yang diberikan oleh guru dan banyak kegiatan yang diikuti di luar kelas, hadir tepat waktu di kelas, mampu berkonsentrasi dalam belajar meskipun banyak godaan di lingkungan sekitar. Namun sebagian siswa yang berusia remaja banyak menghabiskan waktu untuk urusan hiburan yang sifatnya lebih menyenangkan dibandingkan dengan urusan akademik. Hal ini dilihat dari kebiasaan suka begadang, jalan-jalan di mall atau plaza, menonton televisi hingga berjamjam, kecanduan game online serta suka menunda waktu pekerjaan (Savitri, 2011:1). Perilaku menunda kegiatan sampai batas waktu, baik memulai maupun menyelesaikan tugas yang Prokrastinasi akademik akan mengganggu proses belajar siswa karena dengan tindakan ini siswa cenderung belajar dengan tidak maksimal karena kurangnya waktu dan mendatangkan berbagai dampak negatif bagi siswa. Beberapa kerugian siswa yang disebabkan oleh prokrastinasi akademik yaitu banyaknya waktu yang terbuang tanpa menghasilkan sesuatu yang berguna, tugas tidak terselesaikan, atau terselesaikan namun tidak maksimal karena dikejar deadline, sulit berkonsentrasi, merasa cemas, hingga memperoleh hasil belajar yang tidak memuaskan.

Wieber dan Gollwitzer (2010) mengemukakan "Empat faktor penyebab terjadinya perilaku prokrastinasi akademik yaitu rendahnya self regulation, sikap perfeksionis, rendahnya self control, dan rendahnya self efficacy". Munculnya perilaku prokrastinasi akademik ini dapat disebabkan oleh pemikiranpemikiran yang irrasional sebagai salah satu akibat dari rendahnya self regulation misalnya "besok masih bisa", "saya bisa mengerjakan hal ini dengan cepat". Kemudian sikap perfeksionis yang menginginkan segala sesuatu dikerjakan dengan sempurna termasuk tugas sekolah, sehingga siswa menunda penyelesaian tugas dengan alasan masih mencari bahan untuk melengkapi tugas atau masih mengusahakan kesempurnaan hasilnya. Disamping itu adanya keinginan untuk memperoleh kesenangan (reinforcement) sesaat yang lebih menarik juga menjadi penyebab munculnya perilaku prokrastinasi misalnya: memilih jalan-jalan bersama teman di mall atau menonton film daripada belajar sesuai dengan jadwal yang telah dibuatnya. Penyebab lain munculnya perilaku prokrastinasi ini adalah pengaturan waktu yang buruk dari siswa itu sendiri (Ferrari, et al, 1995:78). Kemampuan dalam melakukan pengaturan diri juga dapat menyebabkan kemunculan perilaku prokrastinasi pada siswa.

Banyak siswa yang masih belum menyadari bahwa prokrastinasi jika dijadikan sebagai budaya dalam aktivitas akademik akan mendatangkan banyak kerugian bagi siswa, dimana hal ini bermula dari kurangnya informasi yang diberikan kepada siswa mengenai bahaya prokrastinasi akademik dan bagaimana cara menanggulanginya. Hal-hal yang demikianlah yang dapat menjadi penyebab munculnya prokrastinasi akademik siswa.

Berdasarkan hasil penelitian yang dilakukan oleh Dosi Juliawati (2014) setelah pemberian perlakuan layanan bimbingan kelompok sebanyak enam kali pertemuan pada kelompok eksperimen terjadi pengurangan prokrastinasi akademik siswa sebesar 20,96\%. Dengan demikian dapat dikatakan bahwa layanan bimbingan kelompok dapat dijadikan salah satu alternatif untuk mengurangi prokrastinasi akademik siswa.

Fenomena yang penulis temukan di SMA Adabiah 2 Padang berdasarkan hasil observasi tanggal 20 Mei 2014 ditemukan bahwa masih ada siswa yangmelakukan penundaan dalam kegiatan akademik. Penundaan yang dilakukan siswa diantaranya menunda penyelesaian tugas yang diberikan oleh guru, menunda waktu masuk ke dalam kelas untuk mengikuti pelajaran (hal ini sering terjadi setelah jam istirahat), memilih menyibukkan diri dengan hal yang tidak terlalu penting sementara hal yang mendesak diabaikan (seperti siswa yang diberikan waktu untuk membaca atau membuat tugas, justru mengobrol dan bahkan keluar kelas untuk duduk-duduk di luar kelas), bermain di lapangan, dan kegiatan lain yang kurang bermanfaat pada saat itu.

Selain melakukan obeservasi, penulis juga melakukan wawancara dengan koordinator BK di SMA Adabiah 2 Padang. Berdasarkan wawancara yang telah dilakukan pada tanggal 16 September 2014 diperoleh informasi bahwa 
guru pembimbing di sekolah sering mendapati siswa yang memiliki kecenderungan melakukan penundaan dalam kegiatan belajar, seperti menunda penyelesaian pekerjaan yang diberikan oleh guru hingga menyelesaikannya di sekolah pada jam mata pelajaran lain termasuk pada saat pemberian layanan klasikal.Untuk melengkapi data mengenai prokrastinasi akademik yang terjadi di kalangan siswa SMA Adabiah 2 Padang, penulis juga melakukan wawancara dengan salah seorang guru mata pelajaran yaitu guru mata pelajaran Fisika kelas X pada tanggal 16 September 2014. Dari wawancara yang telah dilakukan diperoleh informasi bahwa guru mata pelajaran sering mendengar siswa menolak ketika diberi tugas atau soal-soal untuk diselesaikan di rumah (pekerjaan rumah) dengan alasan sudah banyak tugas yang diberikan oleh guru lain dan kekurangan waktu istirahat karena tugas yang banyak. Dalam kegiatan belajar di kelas, masih ada siswa yang mengumpulkan tugas melewati batas waktu yang telah ditetapkan. Kemudian masih banyak yang menyelesaikan tugas dengan asal-asalan bahkan tugas yang dikumpulkan ada yang sama persis isi dan bentuknya.

Berdasarkan fenomena yang terjadi, upaya yang dapat dilakukan dalam mengurangi prokrastinasi akademik siswa melalui berbagai strategi maupun pendekatan, salah satunya adalah melalui layanan bimbingan dan konseling. Strategi yang telah diuji dalam penelitian terdahulu adalah pemberian layanan bimbingan kelompok. Oleh karena itu, pemberian layanan informasi dapat dijadikan sebagai alternatif untuk mengurangi masalah prokrastinasi akademik siswa. Pemilihan layanan informasi dilakukan atas pertimbangan bahwa di sekolah yang akan menjadi tempat penelitian ini pemberian layanan informasi belum optimal. Dalam kaitannya dengan prokrastinasi akademik siswa, sering menjadi kenyataan bahwa pemahaman siswa mengenai informasi yang diterimanya dapat membangun perilaku siswa dalam kehidupan sehari-hari terutama dalam kegiatan belajar.

Layanan informasi yang dilaksanakan selama ini belum optimal sehingga perlu dilakukan upaya lain. Beberapa pendekatan pembelajaran yang dapat diaplikasikan dalam pemberian layanan informasi seperti pendekatan konstruktivisme, pendekatan deduktif, pendekatan induktif, pendekatan konsep, pendekatan saintific, dan pendekatan Contextual Teaching and Learning (CTL). Dalam hal ini penulis tertarik untuk menggunakan pendekatan kontekstual (Contextual Teaching and Learning/CTL) dengan prinsip konstruktivisme dalam pemberian layanan informasi. Johnson dalam Rusman (2012:192) mengemukakan beberapa komponen pembelajaran kontekstual yaitu: 1) Menjalin hubungan yang bermakna, 2) Mengerjakan pekerjaan-pekerjaan yang berarti (doing significant work), 3) Melakukan proses belajar yang diatur sendiri (self-regulated learning), 4) Mengadakan kolaborasi, 5) Berpikir kritis dan kreatif, 6) Mengupayakan pencapaian standar yang tinggi, 7) Menggunakan asesmen autentik.

Mengingat masalah prokrastinasi akademik siswa merupakan masalah yang dikhawatirkan menghalangi kesuksesan siswa dalam kegiatan belajar dan sangat penting mendapatkan penanganan segera, maka dari itu penulis menggunakan layanan informasi menggunakan pendekatan Contextual Teaching and Learning (CTL) dengan prinsip konstruktivisme untuk mengurangi prokrastinasi akademik siswa. Melalui pemberian layanan informasi menggunakan pendekatan Contextual Teaching and Learning (CTL) dengan prinsip konstruktivisme siswa diberikan kesempatan untuk mengaitkan pengetahuan yang diperoleh dalam proses pembelajaran dengan kondisi nyata pada kehidupan sehari-hari. Materi yang akan dibahas disesusuaikan dengan permasalahan prokrastinasi akademik yang dialami oleh siswa.

Berdasarkan uraian dan permasalahan tersebut, guru BK berperan untuk menerapkan layanan bimbingan dan konseling sesuai dengan Pola BK 17 plus. Salah satu layanan yang membimbing siswa untuk dapat mengurangi prokrastinasi akademik siswa adalah melalui layanan informasi menggunakan pendekatan Contextual Teaching and Learning (CTL) dengan prinsip konstruktivisme.

\section{METODE PENELITIAN}

Penelitian ini merupakan penelitian eksperimen yang menguji pengaruh diantara variabel yang diteliti. Subjek penelitian meliputi siswa SMA Adabiah 2 Padang yang terdiri dari 23 orang siswa kelas X.3 kelompok eksperimen dan 23 orang siswa kelas X.10 sebagai kelompok kontrol. Instrumen yang digunakan adalah skala prokrastinasi dengan lima alternatif jawaban yaitu Selalu, Sering, Kadang-kadang, Jarang dan Tidak Pernah. Teknik analisis data menggunakan presentase (Anas Sudjono, 2009: 318) dengan rumus sebagai berikut:

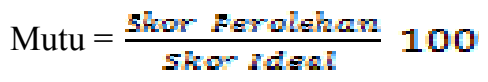

Selanjutnya untuk melihat deskripsi data hasil pretest da posttest digunakan rumus mean (rata-rata), range, skor minimum dan skor maksimum. Menurut Tulus Winarsunu (2002: 59) rumus- rumus tersebut adalah:

1. Mean, yaitu $\mathrm{M}=\frac{\Sigma \mathrm{fm}}{\mathrm{M}}$ 
2. Range, yaitu Range $=(\mathrm{Xt}-\mathrm{Xr})+1$

Keterangan:

$$
\begin{array}{ll}
\boldsymbol{\Sigma} \mathrm{fx} & =\text { Jumlah skor perolehan } \\
\mathrm{N} & =\text { Jumlah responden } \\
\mathrm{M} & =\text { Mean } \\
\mathrm{Range} & =\text { Rentangan dari skor } \\
\mathrm{Xt} & =\text { Skor Tertinggi } \\
\mathrm{Xr} & =\text { Skor Terendah }
\end{array}
$$

Setelah data diolah menggunakan rumus statistik kemudian ditetapkan kriteria penilaian masing-masing data yang diperoleh yang mengacu kepada batasan yang dimodifikasi dari Husaini Usman (2003:94):

Tabel 1

\section{Kriteria Pengolahan Data Deskriptif} Hasil Penelitian

\begin{tabular}{|c|c|c|}
\hline $\begin{array}{c}\text { Kategori } \\
\text { Tingkat } \\
\text { Prokrastinasi } \\
\text { Akademik } \\
\text { Siswa }\end{array}$ & $\begin{array}{c}\text { Rentangan } \\
\text { Kategori }\end{array}$ & Interval \\
\hline Sangat Rendah & $<\mathrm{ST}-4 \mathrm{I}$ & $<51$ \\
\hline Rendah & $\begin{array}{c}\geq \mathrm{ST}-4 \mathrm{I} \mathrm{s} . \mathrm{d}< \\
\mathrm{ST}-3 \mathrm{I}\end{array}$ & $\geq 51 \mathrm{~s} / \mathrm{d}<76$ \\
\hline Sedang & $\begin{array}{c}\geq \mathrm{ST}-3 \mathrm{I} \mathrm{s} . \mathrm{d}< \\
\mathrm{ST}-2 \mathrm{I}\end{array}$ & $\geq 76 \mathrm{~s} / \mathrm{d}<101$ \\
\hline Tinggi & $\geq \mathrm{ST}-2 \mathrm{I} \mathrm{s} . \mathrm{d}<$ \\
$\mathrm{ST}-\mathrm{I}$ & $\geq 76 \mathrm{~s} / \mathrm{d}<101$ \\
\hline Sangat Tinggi & $\geq \mathrm{ST}-\mathrm{I}$ & $\geq 126$ \\
\hline
\end{tabular}

Keterangan:

$\mathrm{ST}=$ Skor maksimal ideal $=5 \times 31=155$

$\mathrm{SR}=$ Skor minimum ideal $=1 \times 31=31$

$\mathrm{I}=$ Interval $=\underline{155-31}=24,8$

$$
5
$$

Untuk melihat perbedaan prokrastinasi akademik siswa antara kelompok eksperimen dengan kelompok kontrol dilakukanlah analisis data dengan menggunakan metode statistik non parametrik yaitu: Test Kolmogorov-Smirnov dua sampel, melalui program SPSS versi 20.

\section{HASIL DAN PEMBAHASAN}

\section{Hasil}

Berdasarkan hasil pengolahan data yang sesuai dengan tujuan penelitian yaitu untuk: a)mendeskripsikan prokrastinasi akademik siswa kelompok eksperimen sebelum dan setelah diberi perlakuan layanan informasi menggunakan pendekatan Contextual Teaching and Learning (CTL) dengan prinsip konstruktivisme, b) mendeskripsikan prokrastinasi akademik siswa kelompok kontrol yang tidak diberi perlakuan layanan informasi menggunakan pendekatan Contextual Teaching and Learning $(C T L)$ dengan prinsip konstruktivisme, c) mengidentifikasi perbedaan prokrastinasi akademik siswa antara siswa kelompok eksperimen yang diberikan layanan informasi menggunakan pendekatan Contextual Teaching and Learning (CTL) dengan prinsip konstruktivisme, dengan siswa kelompok kontrol yang tidak diberi perlakuan layanan informasi menggunakan pendekatan Contextual Teaching and Learning (CTL) dengan prinsip konstruktivisme. Maka dapat diuraikan hasil penelitian sebagai berikut:

Deskripsi Prokrastinasi Akademik Sebelum dan Setelah Diberikan Layanan Informasi Menggunakan Pendekatan Contextual

\begin{tabular}{|c|c|c|c|c|c|c|c|}
\hline & & & & & & & \\
\hline $\begin{array}{l}\mathrm{N} \\
\mathrm{o}\end{array}$ & & $\begin{array}{l}\text { Skor } \\
\text { ideal }\end{array}$ & $\begin{array}{l}\text { Skor } \\
\text { terti } \\
\text { nggi }\end{array}$ & $\begin{array}{c}\text { Skor } \\
\text { teren } \\
\text { dah }\end{array}$ & $\begin{array}{c}\text { Rata- } \\
\text { rata }\end{array}$ & $\begin{array}{c}\text { Rerata } \\
\text { dari } \\
\text { ideal }\end{array}$ & $\begin{array}{c}\text { Katego } \\
\text { ri }\end{array}$ \\
\hline 1 & Pretest & 155 & 121 & 59 & 93,30 & 60,19 & Sedang \\
\hline 2 & Posttest & 155 & 85 & 44 & 60,69 & 39,15 & Rendah \\
\hline
\end{tabular}
Teaching and Learning (CTL) dengan Prinsip Konstruktivisme pada Kelompok Eksperimen

Tabel 2

Skor kondisi prokrastinasi akademik siswa kelompok eksperimen pada pretest dan

Berdasarkan tabel 2 diperoleh skor ratarata hasil pretest siswa adalah 93,30 dengan persentase $60,19 \%$. Dari data tersebut diketahui bahwa prokrastinasi akademik siswa sebelum diberikan layanan informasi menggunakan pendekatan Contextual Teaching and Learning (CTL) dengan prinsip konstruktivisme berada pada kategori sedang, hal ini ditafsirkan sesuai dengan pengklasifikasian yang dimodifikasi dari Husaini Usman pada tabel 4. Sedangkan pada hasil posttest skor yang diperoleh siswa sebesar 60,69 dengan presentase $39,15 \%$ dan diketahui bahwa prokrsinasi akademik siswa setelah diberikan layanan informasi menggunakan pendekatan Contextual Teaching and Learning (CTL) dengan prinsip konstruktivisme berada pada kategori rendah. Berikut ini dijabarkan lebih lanjut melalui skor perolehan individual siswa kelompok eksperimen. 
Tabel 4

Skor kondisi prokrastinasi akademik siswa

kelompok kontrol pada pretest dan posttest

\begin{tabular}{|c|c|c|c|c|c|c|c|}
\hline No & & $\begin{array}{c}\text { Skor } \\
\text { ideal }\end{array}$ & $\begin{array}{c}\text { Skor } \\
\text { tertin } \\
\text { ggi }\end{array}$ & $\begin{array}{c}\text { Skor } \\
\text { teren } \\
\text { dah }\end{array}$ & $\begin{array}{c}\text { Rata- } \\
\text { rata }\end{array}$ & $\begin{array}{c}\text { Rerata } \\
\text { dari } \\
\text { ideal }\end{array}$ & $\begin{array}{c}\text { Katego } \\
\text { ri }\end{array}$ \\
\hline 1. & Pretest & 155 & 121 & 58 & 92,56 & 59,71 & Sedang \\
\hline 2. & Posttest & 155 & 131 & 58 & 88,82 & 67,30 & Sedang \\
\hline
\end{tabular}

Berdasarkan tabel 4 skor rata-rata hasil pretest siswa adalah 92,56 dengan persentase $5971 \%$. Dari data tersebut diketahui bahwa hasil

Tabel 3

Prokrastinasi akademik siswa kelompok eksperimen pada pretest dan posttest

\begin{tabular}{|c|c|c|c|c|c|c|c|}
\hline \multirow{4}{*}{$\begin{array}{l}\mathbf{N} \\
\mathbf{O}\end{array}$} & \multirow{4}{*}{$\mathbf{K R}$} & \multicolumn{6}{|c|}{ Kelompok Eksperimen } \\
\hline & & \multicolumn{3}{|c|}{ Pretest } & \multicolumn{3}{|c|}{ Posttest } \\
\hline & & \multicolumn{2}{|c|}{ Perolehan } & \multirow{2}{*}{$\begin{array}{l}\text { Kate } \\
\text { gori }\end{array}$} & \multicolumn{2}{|c|}{ Perolehan } & \multirow{2}{*}{$\begin{array}{l}\text { Kate } \\
\text { gori }\end{array}$} \\
\hline & & Skor & $\%$ & & Skor & $\%$ & \\
\hline 1. & $\overline{\mathrm{ARL}}$ & 72 & 46,45 & $\mathrm{R}$ & 44 & 28,38 & SR \\
\hline 2. & ABDN & 98 & 63,22 & SD & 62 & 40,00 & $\mathrm{R}$ \\
\hline 3. & AA & 105 & 67,74 & $\mathrm{~T}$ & 57 & 36,77 & $\mathrm{R}$ \\
\hline 4. & AYE & 107 & 69,03 & $\mathrm{~T}$ & 78 & 50,32 & SD \\
\hline 5. & ANP & 88 & 56,77 & SD & 79 & 50,96 & SD \\
\hline 6. & EFE & 80 & 51,61 & SD & 46 & 29,67 & SR \\
\hline 7. & $\mathrm{EF}$ & 103 & 66,45 & $\mathrm{~T}$ & 58 & 37,41 & $\mathrm{R}$ \\
\hline 8. & $\mathrm{FF}$ & 79 & 50,96 & SD & 47 & 30,32 & SR \\
\hline 9. & GR & 97 & 50,96 & SD & 54 & 34,83 & $\mathrm{R}$ \\
\hline 10. & MY & 121 & 78,06 & $\mathrm{~T}$ & 62 & 40,00 & $\mathrm{R}$ \\
\hline 11. & MHP & 88 & 56,77 & SD & 59 & 38,06 & $\mathrm{R}$ \\
\hline 12. & MWA & 89 & 57,41 & SD & 65 & 41,93 & $\mathrm{R}$ \\
\hline 13. & MHS & 120 & 77,41 & $\mathrm{~T}$ & 79 & 50,96 & SD \\
\hline 14. & MRRU & 81 & 52,25 & SD & 85 & 54,83 & SD \\
\hline 15. & NW & 111 & 71,61 & $\mathrm{~T}$ & 60 & 38,70 & $\mathrm{R}$ \\
\hline 16. & PMP & 59 & 38,06 & $\mathrm{R}$ & 45 & 29,03 & SR \\
\hline 17. & RF & 96 & 61,93 & SD & 59 & 38,06 & $\mathrm{R}$ \\
\hline 18. & RP & 90 & 58,06 & SD & 45 & 29,03 & SR \\
\hline 19. & SGA & 83 & 53,54 & SD & 48 & 30,96 & SR \\
\hline 20. & SAA & 93 & 60,00 & SD & 63 & 40,64 & $\mathrm{R}$ \\
\hline 21. & YD & 113 & 72,90 & $\mathrm{~T}$ & 82 & 52,90 & SD \\
\hline 22. & TA & 80 & 51,61 & SD & 57 & 36,77 & $\mathrm{R}$ \\
\hline 23. & LP & 93 & 60,00 & SD & 62 & 40,00 & $\mathrm{R}$ \\
\hline Jum & & 2146 & 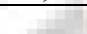 & & 1396 & & \\
\hline
\end{tabular}

Keterangan:

KR $\quad=$ Kode Responden

Sangat Rendah (SR)

Rendah (R)

Sedang (SD)

Tinggi ( $\mathrm{T}$ )

Sangat Tinggi (ST)

$=\geq 51 \mathrm{~s} / \mathrm{d} 76$

$=\geq 76 \mathrm{~s} / \mathrm{d} 101$

$=\geq 101 \mathrm{~s} / \mathrm{d} 126$

$=>126$

Berdasarkan tabel 3 diketahui bahwa secara keseluruhan terjadi perubahan skor perolehan masing-masing siswa kelompok eksperimen sebelum dan setelah diberikan layanan informasi menggunakan pendekatan Contextual Teaching and Learning (CTL) dengan prinsip konstruktivisme. Dengan demikian dapat disimpulkan bahwa secara keseluruhan terjadi pengurangan prokrastinasi akademik siswa kelompok eksperimen.

Deskripsi Prokrastinasi Akademik Siswa Kelompok Kontrol pretest prokrastinasi akademik siswa berada pada kategori sedang, hal ini ditafsirkan sesuai dengan pengklasifikasian yang dimodifikasi dari Husaini Usman pada tabel 4. Sedangkan pada hasil posttest skor yang diperoleh siswa sebesar 88,82 dengan presentase $67,30 \%$ dan tetap berada pada kategori sedang. Berikut ini dijabarkan lebih lanjut melalui skor perolehan individual siswa kelompok kontrol.

Tabel 6

Prokrastinasi akademik siswa kelompok

kontrol

\begin{tabular}{|c|c|c|c|c|c|c|c|}
\hline \multirow{4}{*}{$\begin{array}{l}\mathbf{N} \\
\mathbf{O}\end{array}$} & \multirow{4}{*}{ KR } & \multicolumn{6}{|c|}{ Kelompok Kontrol } \\
\hline & & \multicolumn{3}{|c|}{ Pretest } & \multicolumn{3}{|c|}{ Posttest } \\
\hline & & \multicolumn{2}{|c|}{ Perolehan } & \multirow{2}{*}{$\begin{array}{l}\text { Kate } \\
\text { gori }\end{array}$} & \multicolumn{2}{|c|}{ Perolehan } & \multirow{2}{*}{$\begin{array}{l}\text { Kate } \\
\text { gori }\end{array}$} \\
\hline & & Skor & $\%$ & & Skor & $\%$ & \\
\hline 1. & A & 109 & 70,32 & $\mathrm{~T}$ & 107 & 69,03 & $\mathrm{~T}$ \\
\hline 2. & $\mathrm{AE}$ & 58 & 37,41 & $\mathrm{R}$ & 58 & 37,41 & $\mathrm{R}$ \\
\hline 3. & AFI & 121 & 78,06 & $\mathrm{~T}$ & 119 & 76,77 & $\mathrm{~T}$ \\
\hline 4. & AR & 69 & 44,51 & $\mathrm{R}$ & 72 & 46,45 & $\mathrm{R}$ \\
\hline 5. & $\mathrm{~B}$ & 58 & 37,41 & $\mathrm{R}$ & 60 & 38,70 & $\mathrm{R}$ \\
\hline 6. & $\mathrm{BA}$ & 95 & 61,29 & SD & 77 & 49,67 & SD \\
\hline 7. & CMP & 102 & 65,80 & $\mathrm{~T}$ & 100 & 64,51 & SD \\
\hline 8. & $\mathrm{CT}$ & 90 & 58,06 & SD & 89 & 57,41 & SD \\
\hline 9. & $\mathrm{E}$ & 101 & 65,16 & $\mathrm{~T}$ & 93 & 60,00 & SD \\
\hline 10. & FAM & 82 & 52,90 & SD & 80 & 51,61 & SD \\
\hline 11. & HDK & 106 & 68,38 & $\mathrm{~T}$ & 82 & 52,90 & SD \\
\hline 12. & HSD & 77 & 49,67 & SD & 73 & 47,09 & $\mathrm{R}$ \\
\hline 13. & IA & 81 & 52,25 & SD & 83 & 53,54 & SD \\
\hline 14. & IME & 104 & 67,09 & $\mathrm{~T}$ & 102 & 65,80 & $\mathrm{~T}$ \\
\hline 15. & $\mathrm{IU}$ & 80 & 51,61 & SD & 79 & 50,96 & SD \\
\hline 16. & MA & 78 & 50,32 & SD & 69 & 44,51 & $\mathrm{R}$ \\
\hline 17. & MKR & 108 & 69,67 & $\mathrm{~T}$ & 104 & 67,09 & $\mathrm{~T}$ \\
\hline 18. & NSD & 82 & 52,90 & SD & 78 & 50,32 & SD \\
\hline 19. & RSDN & 107 & 69,03 & $\mathrm{~T}$ & 97 & 62,58 & SD \\
\hline 20. & SDDR & 128 & 82,58 & SDT & 131 & 84,51 & SDT \\
\hline 21. & SDR & 104 & 67,09 & $\mathrm{~T}$ & 98 & 63,22 & SD \\
\hline 22. & TPP & 119 & 76,77 & $\mathrm{~T}$ & 123 & 79,35 & $\mathrm{~T}$ \\
\hline 23. & WD & 70 & 45,16 & $\mathrm{R}$ & 69 & 44,51 & $\mathrm{R}$ \\
\hline \multicolumn{2}{|c|}{ Jumlah } & 2129 & & & 2043 & & \\
\hline
\end{tabular}

Keterangan:

KR

Sangat Rendah (SR)

Rendah (R)

Sedang (SD)

Tinggi (T)

Sangat Tinggi (ST)

Berdasarkan tabel 6 diketahui bahwa hanya sebagian siswa yang mengalami perubahan skor perolehan masing-masing pada kelompok kontrol dan perubahan skor tersebut 
belum menunjukkan terjadinya pengurangan prokrastinasi akademik siswa pada kelompok kontrol. Dengan demikian dapat disimpulkan bahwa tidak terjadi pengurangan prokrastinasi akademik pada keseluruhan siswa kelompok kontrol.

$\begin{array}{lcc}\text { Perbedaan } & \text { Prokrastinasi } & \text { Akademik Siswa } \\ \text { Kelompok } & \text { Eksperimen } \\ \text { Kontrol } & & \text { dan Kelompok }\end{array}$

Tabel 7

Prokrastinasi Akademik Siswa Kelompok Eksperimen dan

Kelompok Kontrol

\begin{tabular}{|c|c|c|c|c|c|c|c|}
\hline \multirow{4}{*}{$\begin{array}{l}\mathbf{N} \\
\mathbf{O}\end{array}$} & \multirow{4}{*}{$\mathbf{K R}$} & \multicolumn{6}{|c|}{ Kelompok Kontrol } \\
\hline & & \multicolumn{3}{|c|}{ Pretest } & \multicolumn{3}{|c|}{ Posttest } \\
\hline & & \multicolumn{2}{|c|}{ Perolehan } & \multirow{2}{*}{$\begin{array}{l}\text { Kate } \\
\text { gori }\end{array}$} & \multicolumn{2}{|c|}{ Perolehan } & \multirow{2}{*}{$\begin{array}{l}\text { Kate } \\
\text { gori }\end{array}$} \\
\hline & & Skor & $\%$ & & Skor & $\%$ & \\
\hline 1. & A & 109 & 70,32 & $\mathrm{~T}$ & 107 & 69,03 & $\mathrm{~T}$ \\
\hline 2. & $\mathrm{AE}$ & 58 & 37,41 & $\mathrm{R}$ & 58 & 37,41 & $\mathrm{R}$ \\
\hline 3. & AFI & 121 & 78,06 & $\mathrm{~T}$ & 119 & 76,77 & $\mathrm{~T}$ \\
\hline 4. & $\mathrm{AR}$ & 69 & 44,51 & $\mathrm{R}$ & 72 & 46,45 & $\mathrm{R}$ \\
\hline 5. & $\mathrm{~B}$ & 58 & 37,41 & $\bar{R}$ & 60 & 38,70 & $\mathrm{R}$ \\
\hline 6. & $\mathrm{BA}$ & 95 & 61,29 & SD & 77 & 49,67 & SD \\
\hline 7. & CMP & 102 & 65,80 & $\mathrm{~T}$ & 100 & 64,51 & SD \\
\hline 8. & $\mathrm{CT}$ & 90 & 58,06 & SD & 89 & 57,41 & SD \\
\hline 9. & $\mathrm{E}$ & 101 & 65,16 & $\mathrm{~T}$ & 93 & 60,00 & SD \\
\hline 10. & FAM & 82 & 52,90 & SD & 80 & 51,61 & $\mathrm{SD}$ \\
\hline 11. & HDK & 106 & 68,38 & $\mathrm{~T}$ & 82 & 52,90 & SD \\
\hline 12. & HSD & 77 & 49,67 & SD & 73 & 47,09 & $\mathrm{R}$ \\
\hline 13. & IA & 81 & 52,25 & SD & 83 & 53,54 & SD \\
\hline 14. & IME & 104 & 67,09 & $\mathrm{~T}$ & 102 & 65,80 & $\mathrm{~T}$ \\
\hline 15. & IU & 80 & 51,61 & SD & 79 & 50,96 & SD \\
\hline 16. & MA & 78 & 50,32 & SD & 69 & 44,51 & $\mathrm{R}$ \\
\hline 17. & MKR & 108 & 69,67 & $\mathrm{~T}$ & 104 & 67,09 & $\mathrm{~T}$ \\
\hline 18. & NSD & 82 & 52,90 & SD & 78 & 50,32 & SD \\
\hline 19. & RSDN & 107 & 69,03 & $\mathrm{~T}$ & 97 & 62,58 & SD \\
\hline 20. & SDDR & 128 & 82,58 & ST & 131 & 84,51 & ST \\
\hline 21. & SDR & 104 & 67,09 & $\mathrm{~T}$ & 98 & 63,22 & SD \\
\hline 22. & TPP & 119 & 76,77 & $\mathrm{~T}$ & 123 & 79,35 & $\mathrm{~T}$ \\
\hline 23. & WD & 70 & 45,16 & $\mathrm{R}$ & 69 & 44,51 & $\mathrm{R}$ \\
\hline \multicolumn{2}{|c|}{ Jumlah } & 2129 & - & & 2043 & & \\
\hline
\end{tabular}

Keterangan:

KR

$=$ Kode Responden

Sangat Rendah (SR)

Rendah (R)

Sedang (SD)

Tinggi ( $\mathrm{T}$ )

Sangat Tinggi (ST)

$=<51$

$=\geq 51 \mathrm{~s} / \mathrm{d} 76$

$=\geq 76 \mathrm{~s} / \mathrm{d} 101$

$=\geq 101 \mathrm{~s} / \mathrm{d} 126$

$=>126$

Berdasarkan data pretest dan posttest yang dapat dilihat pada tabel 7 diketahui bahwa terjadi pengurangan prokrastinasi akademik siswa setelah diberikan layanan informasi menggunakan pendekatan Contextual Teaching and Learning (CTL) dengan prinsip konstruktivisme pada kelompok eksperimen. Pengurangan prokrastinasi akademik siswa pada kelompok eksperimen dengan rata-rata perubahan 21,04\% lebih besar dibandingkan pengurangan prokrastinasi akademik siswapada kelompok kontrol dengan rata-rata perubahan $2,41 \%$.

Secara keseluruhan dapat dilihat adanya perbedaan hasil kelompok eksperimen dengan kelompok kontrol. Hampir keseluruhan siswa pada kelompok eksperimen mengalami pengurangan prokrastinasi akademik setelah diberikan layanan informasimenggunakan pendekatan Contextual Teaching and Learning (CTL) dengan prinsip konstruktivisme, sedangkan pada kelompok kontrol masih terdapat beberapa siswa yang tidak mengalami pengurangan prokrastinasi akademik bahkan ada beberapa siswa yang justru mengalami peningkatan prokrastinasi. Hal ini berarti bahwa pemberian layanan informasi menggunakan pendekatan Contextual Teaching and Learning (CTL) dengan prinsip konstruktivisme efektif untuk mengurangi prokrastinasi akademik siswa.

\section{Pembahasan}

Prokrastinasi Akademik Sebelum dan Setelah Diberikan Layanan Informasi Menggunakan Pendekatan Contextual Teaching and Learning (CTL) dengan Prinsip Konstruktivisme pada Kelompok Eksperimen

Berdasarkan hasil penelitian yang dilakukan melalui eksperimen dengan materi yang berkaitan dengan prokrastinasi akademik, siswa pada kelompok eksperimen secara keseluruhan menunjukkan adanya pengurangan prokrastinasi akademik secara signifikan antara sebelum dan sesudah mengikuti layanan informasi menggunakan pendekatan Contextual Teaching and Learning (CTL) dengan prinsip konstruktivisme. Menurut Prayitno (2012:50) tujuan umum layanan informasi adalah dikuasainya informasi tertentu oleh peserta layanan. Dalam kaitannya dengan prokrastinasi akademik siswa, sering menjadi kenyataan bahwa pemahaman siswa mengenai informasi yang diterimanya dapat membangun perilaku siswa dalam kehidupan sehari-hari terutama dalam kegiatan belajar. Melalui layanan informasi yang dikhususkan untuk mengurangi prokrsatinasi akademik siswa, hal-hal yang mengganggu siswa dalam kegiatan belajar diharapkan dapat berkurang sehingga siswa dapat mengurangi prokrastinasi akademiknya.

Pendekatan yang dipandang tepat untuk mengatasi masalah prokrastinasi akademik siswa melalui layanan informasi yang diberikan dalam format pembelajaran di kelas/klasikal salah satunya adalah pendekatan Contextual Teaching and Learning (CTL) dengan prinsip konstruktivisme. Pengembangan pendekatan Contextual Teaching and Learning (CTL) dengan prinsip konstruktivisme dalam 
pelaksanaan layanan informasi dapat dilakukan dengan memperhatikan lima elemen yang dijelaskan oleh Zahorik (dalam Yatim Riyanto, 2012:165) sebagai berikut:

a. Pengaktifan pengetahuan yang sudah ada (activating knowladge)

b. Pemerolehan pengetahuan baru (acquiring knowladge) dengan cara mempelajari secara keseluruhan dahulu, kemudian memperhatikan detailnya.

c. Pemahaman pengatahuan (understanding knowladge), yaitu dengan cara menyusun: a) konsep sementara (hipotesis), b) melakukan sharing kepada orang lain agar mendapat tanggapan (validasi) dan atas dasar tanggapan itu, c) konsep tersebut direvisi dan dikembangkan, d) mempraktikkan pengetahuan dan pengalaman tersebut, e)melakukan refleksi (reflection knowladge) terhadap strategi pengembangan pengetahuan tersebut.

Dengan dilaksanakan layanan informasi sesuai lima elemen tersebut, dan didukung oleh materi bahasan yang berkaitan dengan prokrastinasi akademik, siswadapat memehami hal-hal terkait prokrastinasi akademi merupakan kebiasaan buruk dalam belajar yang dapat menghambat kesuksesan dalam belajar. Siswa juga dapat berkomitmen untuk mengaplikasikan pengetahuan yang telah diperoleh melalui layanan informasi yang telah diikuti dalam rangka mengurangi prokrastinasi akademik.

\section{Prokrastinasi Akademik Siswa Kelompok Kontrol}

Berdasarkan data hasil penelitian, perbedaan pretest dan posttest pada kelompok kontrol yang berjumlah 23 orang siswa terdapat 17 orang siswa yang mengalami pengurangan prokrastinasi akademik. Sedangkan yang mengalami peningkatan terdapat 5 orang siswa dan yang tidak mengalami perubahan yaitu 1 orang siswa. Perubahan yang tidak signifikan pada kelompok kontrol tersebut dikarenakan siswa tidak mendapatkan perlakuan khusus yaitu layanan informasi menggunakan pendekatan Contextual Teaching and Learning (CTL) dengan prinsip konstruktivisme. Dengan demikian, siswa kelompok kontrol secara keseluruhan tidak mengalami pengurangan prokrastinasi akademik secara signifikan.

\section{Perbedaan Prokrastinasi Akademik Siswa Kelompok Eksperimen dan Kelompok Kontrol}

$\begin{array}{cccc}\text { Hipotesis dalam penelitian } & \text { ini yaitu } \\ \text { "terdapat perbedaan } & \text { yang } & \text { signifikan } \\ \text { prokrastinasi } & \text { akademik } & \text { siswa } & \text { kelompok }\end{array}$

eksperimen yang mengikuti layanan informasi menggunakan pendekatan Contextual Teaching and Learning (CTL) dengan prinsip konstruktivisme dan kelompok kontrol yang tidak mengikuti layanan informasi menggunakan pendekatan Contextual Teaching and Learning (CTL) dengan prinsip konstruktivisme". Setelah dilakukan pengujian hipotesis dengan Two Sample Kolmogorov-Smirnov Test menggunakan program SPSS versi 20diperoleh bahwa memang terdapat perbedaan skor pengurangan prokrastinasi akademik siswa antara kelompok eksperimen dan kelompok kontrol.

Perbedaan hasil posttest kelompok eksperimen dan kelompok kontrol salah satunya disebabkan oleh perbedaan perlakuan yang diberikan pada masing-masing kelompok. Layanan informasi menggunakan pendekatan Contextual Teaching and Learning (CTL) dengan prinsip konstruktivisme merupakan layanan yang lebih efektif dalam mengurangi prokrastinasi akademik siswa. Sebagaimana dikemukakan oleh Tohirin (2009:147) layanan informasi bertujuan agar individu memahami berbagai informasi untuk mencegah timbulnya suatu masalah, pemecahan suatu masalah, dan untuk memelihara serta mengembangkan potensi individu agar dapat mengaktualisasikan hakhaknya sehingga tercipta kemandirian.

Kemudian perbedaan prokrastinasi akademik siswa kelompok eksperimen dan kelompok kontrol ini selain dipengaruhi oleh perbedaan perlakuan juga dapat dijelaskan dari sudut siswa terkait dengan faktor-faktor yang dapat mempengaruhi prokrastinasi akademik sebagaimana yang dijelaskan oleh Wieber dan Gollwitzer (2010) yaitu self-regulation, sikap perfeksionis, self control, dan self efficacy. Kondisi keempat faktor tersebut tentunya berbeda-beda pada masing-masing siswa dari waktu ke waktu.

Dengan demikian, layanan informasi menggunakan pendekatan Contextual Teaching and Learning (CTL) dengan prinsip konstruktivisme membantu siswa untuk terlibat dalam menemukan materi yang dipelajari kemudian memaknai dan menghubungkannya dengan situasi kehidupan nyata serta mengaplikasikan materi yang disampaikan dalam layanan informasi ke dalam kehidupan sehari-hari. Dan melalui kegiatan ini diharapkan dapat mengurangi prokrastinasi akademik siswa.

\section{KESIMPULAN DAN SARAN \\ 1. Kesimpulan}

Berdasarkan temuan dari penelitian ini yaitu: (1) kondisi prokrastinasi akademik siswa kelompok eksperimen setelah diberikan layanan informasi menggunakan pendekatan Contextual Teaching and Learning (CTL) dengan prinsip 
konstruktivisme berada pada kategori rendah dengan skor rata-rata 60,69, (2) Kondisi prokrastinasi akademik siswa kelompok kontrol yang tidak diberikan layanan informasi menggunakan pendekatan Contextual Teaching and Learning (CTL) dengan prinsip konstruktivisme berada pada kategori sedang dengan skor rata-rata 88,82 , (3) terdapat perbedaan yang signifikan pada skor prokrastinasi akademik siswa antara kelompok eksperimen yang diberi perlakuan layanan informasi menggunakan pendekatan Contextual Teaching and Learning (CTL) dengan prinsip konstruktivisme dan kelompok kontrol yang tidak diberi perlakuan. Hal ini menunjukkan bahwa layanan informasi menggunakan pendekatan Contextual Teaching and Learning (CTL) dengan prinsip konstruktivisme efektif untuk mengurangi prokrastinasi akademik siswa.

\section{Saran}

a. Guru Bimbingan dan Konseling, untuk terus meningkatkan dan mengembangkan layanan bimbingan dan konseling terutama layanan informasi menggunakan pendekatan Contextual Teaching and Learning (CTL) dengan prinsip konstruktivisme untuk mengupayakan berkurangnya siswa yang mengalami prokrastinasi akademik pada kategori sedang ataupun tinggi. Kemudian mengaktifkan fungsi pengembangan dan pemeliharaan bimbingan dan konseling terhadap siswa yang mengalami prokrastinasi akademik pada kategori rendah maupun sangat rendah agar terjaga kondisi baik tersebut.

b. Bagi peserta didik yang telah mengikuti layanan informasi menggunakan pendekatan Contextual Teaching and Learning (CTL) dengan prinsip konstruktivisme diharapkan dapat mengurangi prokrastinasi akademik dan agar tidak bosan untuk mengikuti kegiatan-kegiatan yang diadakan oleh guru bimbingan dan konseling.

c. Bagi peneliti selanjutnya diharapkan dapat melakukan penelitian dengan jenis layanan bimbingan dan konseling yang lainnya.
Tidak diterbitkan. Padang: Pascasarjana UNP.

Ferrari, J.R, Johnson, J.L, \& McCown, W.G. 1995. Procrastination and Task Avoidence: Theory, Research and Treatment. New York: Plenum Press.

Gollwitzer, P.M., Wieber, F. 2010. “Overcoming Procrastination through Planning". Philosophical Essays on Procrastination. (pp.185-205).

Husaini Usman. 2003. Pengantar Statistik. Jakarta: Bumi Aksara.

Innayatun Naim. 2012. Efektivitas Pembelajaran Matematika dengan Mengguanakan Pendekatan Kontekstual melalui Metode Teams Groups Tournament (TGT) terhadap Pemahaman Konsep dan Motivasi Belajar Siswa.. Skripsi. Tidak diterbitkan. Program Studi Matematika Universitas Islam Negeri Sunan Kalijaga.

Prayitno. 2002. Seri Latihan Keterampilan Belajar. Jakarta: Dirjen Pendidikan Tinggi Proyek Peningkatan Manajemen Pendidikan Tinggi Departemen Pendidikan Nasional.

2012. Jenis Layanan dan Kegiatan Pendukung Konseling. Padang: PPK BK FIP UNP.

Rusman. 2012. Model-Model Pembelajaran. Jakarta: PT Raja Grafindo Persada.

Tohirin. 2009. Bimbingan dan Konseling di Sekolah dan Madrasah (Berbasis Integrasi). Jakarta: Rajawali Press.

Tulus Winarsunu. 2002. Statistik dalam Penelitian Psikologi\&Pendidikan. Malang: UMM.

Wina Sandjaya. 2006. Strategi Pembelajaran berorientasi Standar Proses Pendidikan. Jakarta: Prenada Media Group.

Yatim Riyanto. 2012. Paradigma Baru Pembelajaran. Jakarta: Kencana.

\section{KEPUSTAKAAN}

Anas Sudijono. 2009. Pengantar Evaluasi Pendidikan. Jakarta: Raja Grafindo Persada.

Dosi Juliawati. 2014. "Efektifitas Layanan Bimbingan Kelompok untuk Mengurangi Prokrastinasi Akademik Siswa". Tesis. 


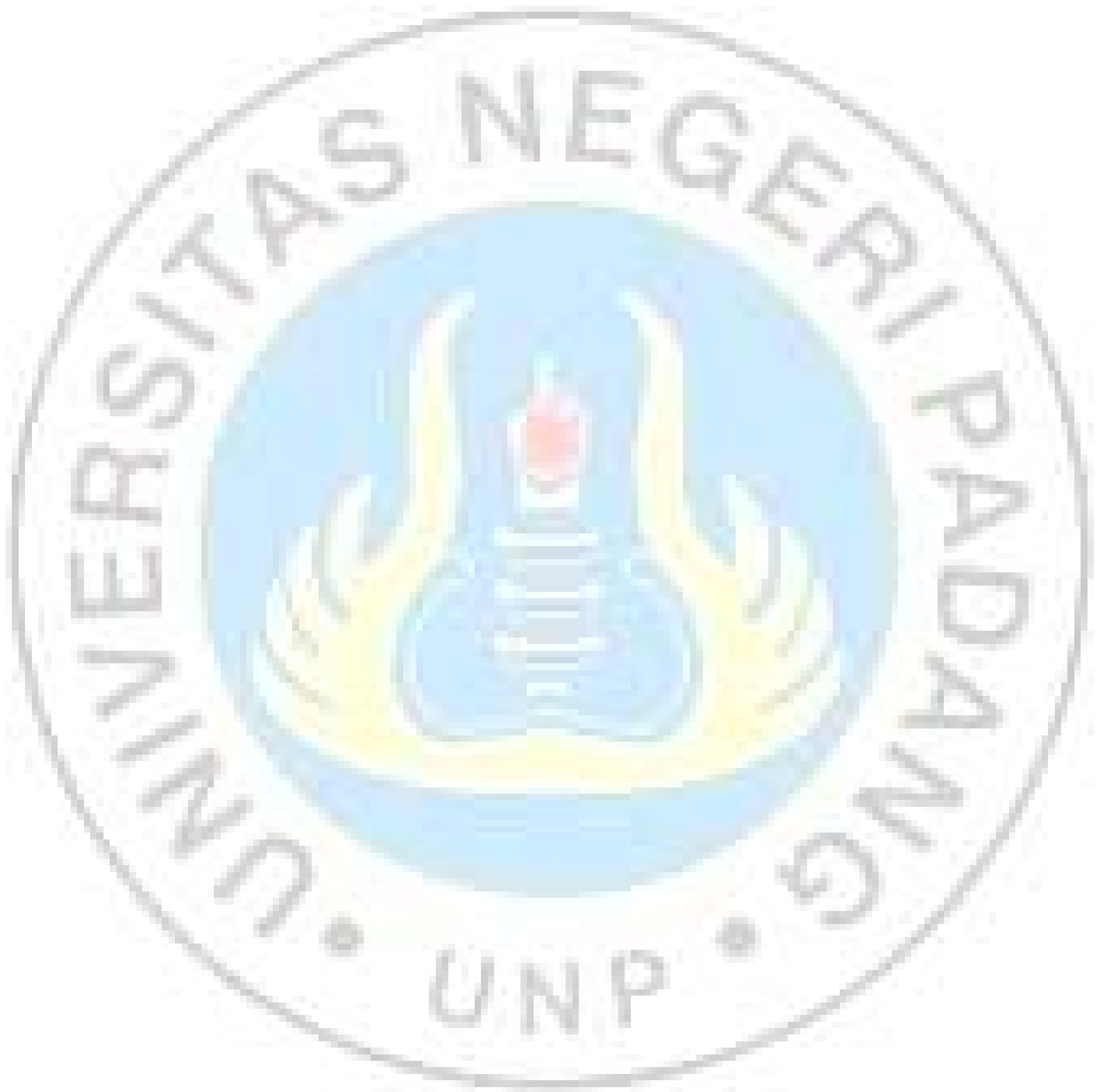

